\title{
The Anti-Inflammatory and Immunosuppressive Properties of Inhaled Anaesthetics - Data from Experimental Studies and Clinical Implications
}

\author{
Mariusz Mielniczuk ${ }^{1,2 *}$, M.D., Ph.D \\ ${ }^{1}$ Department of Anaesthesiology and Intensive Therapy, Antoni Jurasz University Hospital No.1, Bydgoszcz, \\ Poland \\ ${ }^{2}$ Department of Paediatric Anaesthesiology and Intensive Therapy, Antoni Jurasz University Hospital No.1, \\ Bydgoszcz, Poland
}

*Corresponding Author: Mariusz Mielniczuk, Department of Anaesthesiology and Intensive Therapy, Department of Paediatric Anaesthesiology and Intensive Therapy, Antoni Jurasz, University Hospital No.1, Bydgoszcz, Poland, Email: mmiel5@wp.pl

\begin{abstract}
Inhaled anaesthetics are commonly used as an element of general anaesthesia. Experimental and clinical studies proved that these substances can affect the immune system of the patient subjected to anaesthesia. In patients with no serious systemic diseases, the above effect is transient and clinically irrelevant. However, in patients with significant disorders of the inflammatory response, the prognosis may improve or worsen depending on the type of systemic pathology.
\end{abstract}

The available data from few clinical trials as well as in vitro and in vivo experimental studies are partly contradictory, which may respectively result from heterogeneity of the evaluated groups of patients, differences in the extent and duration of surgical procedures, and from different methodology of research experiments.

In the presented review paper, data from so far conducted experimental studies has been collected and the attempt was made to show potential clinical implications.

\section{INTRODUCTION}

The results of experimental in vitro studies report immunosuppressive effects of volatile anaesthetics depending on the duration of exposure and a dose used on various immune cells.

Volatile anaesthetics are known as substances having beneficial immunomodulatory properties not only in the inflammatory reaction induced by ischemia-reperfusion or hypoxia-reoxidation but also in other states of the acute inflammatory response (1-4).

It was shown that the use of volatile anaesthetics (such as sevoflurane, isoflurane or desflurane) significantly reduces the expression of inflammatory mediators, such as monocyte chemoattractant protein-1 (MCP-1), cytokine induced neutrophil chemoattraktant-1 (CINC-1), IL- 6 and IL- 8 by the cells of damaged tissue and modifies the expression of neutrophil integrin $\mathrm{CD} 11 \mathrm{~b}$ and selectin $\mathrm{CD} 62 \mathrm{~L}$ which are the inflammatory response molecules playing a key role in the acute organ failure (5-7).

Several clinical studies have shown that the use of volatile anaesthetics in patients undergoing lung $(4,8)$, heart (9) or liver surgery (10) resulted in fewer postoperative complications.

The described effects of inhaled anaesthetics in the clinical conditions may largely correspond to their immunomodulatory properties demonstrated in the experimental in vitro and in vivo studies.

Inhaled anaesthetics have a depressant effect on both specific and nonspecific immune response. An influence of volatile anaesthetics was reported on most immune system cells.

\section{THE IMPACT OF INHALED ANAESTHETICS ON THE FUNCTIONS OF POLYMORPHONUCLEAR NEUTROPHILS (PMN)}

In the description of inhibiting the bactericidal function of human neutrophils in vitro Welch et al. suggested that this property is connected with 
the mechanism responsible for eliminating pathogens which is dependent on the production of reactive oxygen species (ROS) (11).

This report was confirmed by another study proving that the production of ROS by activated neutrophils was inhibited by halothane, enflurane, isoflurane and sevoflurane (12).

It is suggested that the mechanism by which volatile anaesthetics impair the release of ROS from neutrophils may be associated with a direct inhibitory effect on NADPH oxidase or with suppressing some components of the NADPH oxidase control pathway such as protein kinase $\mathrm{C}(12,13)$.

The impaired release of ROS, caused by volatile anaesthetics, results in the inhibition of the primary inflammatory response by reducing the adhesion of neutrophils to endothelial cells. ROS released from neutrophils are in fact a stimulus for the upregulation of endothelial adhesive molecules such as P-selectins and intercellular adhesion molecule (ICAM)-1, which respectively participate in rolling along the endothelium, the slowdown and further adhesion of neutrophils to endothelial cells (14, $15)$.

Numerous evidence justified the role of neutrophils in the ischemic and later reperfused myocardium as a good model of primary inflammatory damage leading to organ dysfunction (16).

Data obtained from experimental and clinical studies suggests that isoflurane and sevoflurane may have protective effects in the conditions of ischemia-reperfusion with simultaneous reducing ROS production by neutrophils and post-ischemic adhesion of neutrophils to endothelial cells (17). These properties of volatile anaesthetics may be a part of the phenomenon called anaesthetic preconditioning of the ischemic myocardium (18).

Frohlich et al. showed that halothane, enflurane and sevoflurane caused weakness, while desflurane significantly increased the activity of peripheral blood neutrophils (12). Anaesthesia induced by isoflurane had little effect on phagocytosis of E. coli (19).

The in vitro study stated that isoflurane-induced anaesthesia weakened the phagocytic activity depending on the duration of exposure (20).

In their clinical study Erol A. et al. investigated the influence of anaesthesia using desflurane, sevoflurane and propofol on phagocytosis and the respiratory burst activity of polymorphonuclear leukocytes isolated from bronchoalveolar lavage (21). It was shown that desflurane and sevoflurane, in contrast to propofol which stimulates leukocyte activity, do not influence the phagocytic activity and ROS production-dependent elimination of pathogens.

Horn et al. reported a promoting action of sevoflurane on binding of platelets to the surface of lymphocytes, neutrophils and monocytes (22). Sevoflurane increases the expression of P-selectin by affecting the transcription factor AP-1 (activator protein 1), a regulator and a mediator in adhering platelets to leukocytes (22). The above study did not describe similar properties when using desflurane.

In the in vivo experimental study, Kusza et al. investigated the effects of anaesthesia using halothane and isoflurane on peripheral microcirculation in the cremaster muscle (23).

The observed behaviour of leukocytes during anaesthesia using halothane contributed to a better perfusion of capillaries.

During halothane anaesthesia, there was a significantly lower level of rolling leukocytes and leukocytes that adhere to the endothelium of postcapillary venules.

A decrease in accumulation of activated leukocytes is associated with reduced levels of ROS, which may improve perfusion of capillaries directly by preventing endothelial oedema and microthrombosis, as well as indirectly by dilating the arterial part of microcirculation, especially resistance arterioles and precapillary sphincters.

In another study, Kusza et al. studied the effects of halothane and isoflurane on the behaviour of leukocytes at the level of microcirculation after experimentally induced cardiac arrest using a cremaster muscle rat model and in vivo microscopy (24).

The presented study showed that anaesthesia using halothane at the concentration of 1MAC attenuated the harmful effect of cardiac arrest on peripheral microcirculation by significantly reducing the number of leukocytes that transmigrate into the extravascular space, the lack of swelling in the post-capillary venules endothelium and by increasing numbers of functional capillary density. In the same experimental in vivo model, Mielniczuk et al. showed that sevoflurane reduces the 
The Anti-Inflammatory and Immunosuppressive Properties of Inhaled Anaesthetics - Data from Experimental Studies and Clinical Implications

development of systemic inflammatory response observed at the level of microcirculation in the conditions of experimentally induced haemorrhagic shock (25).

A better capillary perfusion was observed together with reduced number of rolling leukocytes and those attached to the postcapillary endothelium in the conditions of shock during sevoflurane anaesthesia.

In the in vitro experiment, Mobert et al. evaluated an inhibitory effect of inhaled anaesthetics on the interactions between neutrophils and human endothelial cells (26).

The adhesion of PMNs, derived from the human umbilical venous blood (HUVECs), to endothelial cells was induced by the stimulation of PMNs and/or HUVECs.

The described experiment showed that halothane, isoflurane and sevoflurane at the concentration of 1-2 MAC inhibit the adhesion of neutrophils to endothelial cells. This effect was due to reduced expression of the molecule $\mathrm{CD} 11 \mathrm{~b}$ on the surface of neutrophils. Lucchinetti E. et al. studied the effect of sevoflurane used at the concentration of 0.5-1.0 vol\% on the course of a 15 -minute ischemiareperfusion of the upper extremity (27). The suppressed leukocyte activation was demonstrated together with the inhibition of their interaction with the vascular endothelium, assessed as the level of expression of the adhesive molecule $\mathrm{CD} 11 \mathrm{~b}$. In the in vitro experiment, Feng J. et al. evaluated the impact of pre-conditioning of endothelial cells with isoflurane, and the subsequent incubation in the conditions deficient in oxygen and glucose (28). It was shown that protection of endothelium ensured by isoflurane is based on activating protein kinase $\mathrm{C}$ (PCK) and mitochondrial ATP-sensitive potassium channels.

\section{THE IMPACT OF INHALED ANAESTHETICS ON THE FUNCTION OF MACROPHAGES}

Most experimental in vivo and in vitro studies dealing with the effects of volatile anaesthetics on the function of monocytes and macrophages involve the evaluation of the function of macrophages isolated from the alveoli. For example, in mice in response to influenza infection, halothane inhibits intra-alveolar macrophage recruitment (29).

The vivo study conducted on a rat endotoxaemia model showed that isoflurane reduces the release of pro-inflammatory IL-1 $\beta$ cytokine whose concentration was determined in bronchoalveolar lavage fluid (BALF) (30).

Tschaikowsky et al. described an increased expression of inducible nitric oxide synthase (iNOS) in murine macrophages under the influence of volatile anaesthetics (halothane, enflurane, isoflurane and desflurane) after previous stimulation with bacterial lipopolysaccharide (LPS) and IFN- $\gamma$ (31).

It is probable that co-stimulation of cells with LPS and IFN- $\gamma$ activates iNOS expression by influencing the transcription regulatory factors such as NF- $\kappa$ B and IRF-1 (an INF-dependent transcription factor). It is postulated that inhaled anaesthetics have no effect on this type of genetic regulation of transcription. The antiinflammatory properties of volatile anaesthetics were also demonstrated in other animal models describing a model of acute lung injury caused by endotoxaemia (32).

In opposition to these, there are other results of experimental studies showing the inhibition of LPS-induced iNOS expression in rat or murine macrophages caused by volatile anaesthetics (halothane, enflurane, isoflurane and desflurane) as well as the suppression of NO release by isoflurane or sevoflurane $(31,33,34)$. It is believed that this mechanism of action of inhaled anaesthetics depends on the inhibition of intracellular calcium accumulation and decreased activity of the AP-1transcription factor.

\section{THE IMPACT OF VOLATILE ANAESTHETICS ON THE FUNCTION OF NK CELLS}

Natural Killer cells (NK cells) are essential for the elimination of tumour cells at an early stage of cancer, including metastases. A dysfunction of NK cells in the perioperative period is associated with an increased risk of death in cancer patients.

Many studies that evaluate the in vitro cell response after surgery and anaesthesia prove the impaired cytotoxic activity of NK cells.

In the in vitro experimental study, Woods and Griffitys demonstrated that volatile anaesthetics such as halothane and enflurane reversibly inhibit the activity of NK cells in proportion to the concentrations used (35). In this study, NK cells returned to full activity 1 hour after the exposure to inhaled anaesthetics. 
The Anti-Inflammatory and Immunosuppressive Properties of Inhaled Anaesthetics - Data from Experimental Studies and Clinical Implications

In mice, in both in vivo and in vitro experimental conditions halothane and isoflurane inhibited the increased IFN treatmentinduced cytotoxicity of NK cells isolated from the spleen (36). In addition, studies on animal models showed that the suppression of NK cell activity induced by halothane and isoflurane caused a rapid progression of neoplastic disease and the appearance of distant metastases (37, $38)$.

Although the exact mechanism responsible for a direct depressant effect of volatile anaesthetics on the NK cells activity remains unclear, it is believed that they can directly activate CD8 T lymphocytes, which in turn leads to reduced cytotoxic properties of NK cells. The in vitro study evaluating the functions of cell lines isolated from the splenic parenchyma of anaesthetized mice demonstrated that the removal of $\mathrm{CD} 8+$ lymphocytes from the immediate vicinity of NK cells restored the ability of NK cells to respond to IFN stimulation (39).

\section{THE IMPACT OF Volatile ANAESTHETICS ON THE FUNCTION OF LYMPHOCYTES}

Various studies have shown inhibitory effects of volatile anaesthetics on the proliferation of lymphocytes and the suppressive activity of these drugs on the release of cytokines by peripheral blood mononuclear cells (PBMC) (40-42).

Splenic $T$ cells isolated from the rats anaesthetized with halothane at the concentration of 1 vol $\%$ for 5 hours displayed reduced proliferative capacity and impaired ability to express the molecule CD25, an $\alpha$ IL-2 chain receptor (41).

The vitro study using human PBMC showed that the exposure of cells to halothane at the concentrations of $1 \mathrm{vol} \%$ for 60 minutes impaired surface binding of lymphocytes both to immunoglobulins and mitogen concanavalin A (ConA), the phenomenon was reversible after 24 hours (40). Resistance to the action of mitogens such as ConA substantially impairs lymphocyte ability of blastic transformation as well as the consequent production and the release of cytokines, while in B cells it additionally blocks the secretion of antibodies.

The in vitro exposure of lymphatic cells to halothane, sevoflurane, isoflurane and enflurane inhibits the release of IFN- $\gamma$, IL- $1 \beta$ and TNF- $\alpha$ (42).
The induction of cell apoptosis is one of the mechanisms though which inhaled anaesthetics inhibit the function of lymphatic cells.

In vitro, isoflurane and sevoflurane directly induce the phenomenon of apoptosis in human peripheral blood lymphocytes depending on a dose and the duration of exposure (43).

It was shown that the induction of apoptosis is accompanied by increased levels of activated caspase-3 (CASP3) in the analyzed lymphatic cells (43). At the same time, it was shown that isoflurane limphotoxicity was greater than sevoflurane limphotoxicity.

Based on these results Loop et al. found that sevoflurane and isoflurane induce the cellular apoptosis pathway by influencing the release of cytochrome $\mathrm{c}$ from mitochondria into the cytoplasm in human $\mathrm{T}$ lymphocytes depending on the concentration used (44).

It is believed that the loss of cytochrome $\mathrm{C}$, as a part of the electron transfer chain, induced by volatile anaesthetics, destabilizes the mitochondrial membrane potential and significantly impairs the lymphocytic synthesis of adenosine triphosphate (ATP) leading to the activation of caspases, induction of apoptosis and cell death.

Furthermore, a decrease in the mitochondrial transmembrane potential can induce intracellular production of peroxides and other ROS, which in turn activates protein kinase $\mathrm{C}$ (PKC) and the so-called mitogen-activated protein kinases (MAPK).

Loop et al. reported that sevoflurane inhibited the activation of the AP-1 transcription factor (activator protein-1) in human $\mathrm{T}$ lymphocytes, and that the inhibition of AP-1 was associated with interference with the p38 MAPK pathway through increased phosphorylation of $\mathrm{p} 38 \gamma / \mathrm{p} 38 \delta$ isoforms (45). Therefore, it is believed that a decrease in the mitochondrial transmembrane potential, the release of cytochrome c from mitochondria and interference with the MAPK pathway may underlie the suppression of lymphatic cells induced by volatile anaesthetics.

The use of inhaled anaesthesia in response to surgical trauma is connected with more reduced number of $\mathrm{T}$ lymphocytes and HLA-DR expression compared to the surgery done in total intravenous anaesthesia (TIVA) (46). In addition, after anaesthesia using isoflurane the Th1/Th2 ratio decreased significantly, while it 
The Anti-Inflammatory and Immunosuppressive Properties of Inhaled Anaesthetics - Data from Experimental Studies and Clinical Implications

remained unchanged after the use of propofol (47).

In the in vitro study, Schneemilch et al. investigated the impact of various anaesthetics on the function of mononuclear cells (48). Peripheral blood mononuclear cells obtained from healthy donors were activated by a strong mitogen, phytohemagglutinin (PHA), in the presence or absence of various concentrations of thiopental, propofol, fentanyl, sufentanil, sevoflurane, nitrous oxide as well as the combinations of these anaesthetics.

Lymphatic cell proliferation was assessed using titration of thymidine uptake.

The interleukin-2 production and the release of soluble IL-2 receptor were determined using enzyme immunoassays and was a measure of lymphocyte activation.

It was shown that thiopental and nitrous oxide have immunosuppressive activity and that sevoflurane may have beneficial effects on the immune system by reducing the immunosuppressive action of both these intravenous anaesthetics.

The rats inhaled with halothane for up to 5 hours showed reduced proliferation and expression of the IL-2 receptor in lymphocytes isolated from the spleen and activated by the mitogen (40).

Mitsuhata et al. examined the effects of volatile anaesthetics (sevoflurane, isoflurane, enflurane) at the concentrations corresponding to the clinical conditions on the release of cytokines by stimulated human peripheral mononuclear cells (PBMC). A reduction in the release of IL- $1 \beta$ and TNF- $\alpha$ was found together with no influence on the IL-2 secretion (42).

Schneemilch et al. demonstrated that volatile anaesthetics had variable effects on the function of PBMC: the exposure to nitrous oxide reduced proliferative capacity of PBMC activated by PHA, while the exposure to sevoflurane did not had a similar effect (48).

Surprisingly, the combination of the two volatile anaesthetics slightly increased the proliferation rate suggesting a protective effect of sevoflurane.

Interestingly, the comparable compensating effect was achieved by the exposure of PBMC to thiopental and sevoflurane with nitrous oxide.

The possible molecular mechanisms involved in inhibiting the function of $\mathrm{T}$ lymphocytes in response to volatile anaesthetics may be connected with the abnormal inflow of calcium, modulation of enzymatic balance between adenylate cyclase and phosphodiesterase, impaired signal transduction and gene transcription, the inhibition of nitric oxide production and expression of inducible nitric oxide synthase $(31,40)$.

\section{THE STRUCTURE OF INHALED ANAESTHETICS PARTICLES AND IMMUNOMODULATORY EFFECTS}

In their in vitro study, Urner M. et al. took on determining the component structure of the inhaled anaesthetic molecule responsible for the immunomodulatory effects (49).

The inflammatory response after simultaneous exposure to endotoxin and sevoflurane, diethyl ether or other water-soluble molecules containing trifluorided carbon atoms $(\mathrm{CF} 3)$ was evaluated in the cells of alveolar epithelium in rats and human microvascular endothelial cells and neutrophils.

In the epithelial and endothelial cells, the expression of inflammatory mediators in response to the stimulation with LPS was dosedependent and decreased after the exposure to sevoflurane and other compounds that contained the $\mathrm{CF} 3$ groups.

As a result of exposure to the compounds containing the $\mathrm{CF} 3$ groups, chemotactic activity of neutrophils was reduced together with the expression of surface molecules $\mathrm{CD} 11 \mathrm{~b}$ and CD62L.

It was shown that the CF3 groups were responsible for the immunomodulatory effect of volatile anaesthetics (reduced expression of MCP-1, IL-6, IL-8, CD11b, CINC-1; increased CD62L).

Attenuated expression of inflammatory mediators described by Urner et al., observed during conditioning with sevoflurane is consistent with the results of previously described studies, while increased expression of MCP-1 was typical of diethyl ether (50). This suggested that diethyl ether had proinflammatory effect, while fluorinated carbon groups were essential for the cytoprotective effect of volatile anaesthetics.

According to Urner et al., suppression of the inflammatory reaction after stimulation with LPS can be demonstrated in a wide range of different subclasses of organic compounds 
(alcohols, carboxylic acids, amino acids, esters and amides) carrying fluorinated alkyl substituents on the assumption that the biological effect is associated with the function group (CF3) and not with the basic structure of the molecule.

There were no decreased levels of inflammatory mediators (MCP-1) during the exposure of AECs to chloroform, suggesting that the cytoprotective effects are not typical of all trihalogenic groups (trichloro-, tribromo-) but can be clearly attributed to the presence of trifluorided groups (CF3).

At present, due to coexistence of the anaesthesia effect, the clinical use of beneficial immunomodulatory properties of volatile anaesthetics is limited to the patients who are well-monitored and mechanically ventilated in the operating room and intensive care unit.

The possibility to use immunosuppressive activity of the fluorinated organic substances on a larger scale is focused on developing the compound that could be injected intravenously, non-toxic and devoid of anaesthetic properties.

\section{SUMMARY}

Most of the research data comes from the in vitro studies, and do not take into account the impact of multiple pathophysiological mechanisms present in living organisms whose task is to restore and preserve full homeostasis.

In vitro, all anaesthetics can influence the inflammatory response, but a degree of this impact depends on the applied concentrations, research techniques used for cell separation and / or cell culture and a research model.

Many in vivo studies suggest that if an applicable organism is not affected by systemic pathology, the immunomodulatory effects of anaesthesia do not have permanent outcomes. But in patients with a pre-existing immune system dysfunction, sepsis and multiple organ failure, as well as in patients with a high risk of perioperative complications, the type of used anaesthetic and the method of anaesthesia may have clinical implications.

Anaesthetics may interfere in various areas of the immune system, both directly through the impact on functioning of immune cells and indirectly by modulating the stress response.

\section{Conclusions}

1. The immunosuppressive effect of volatile anaesthetics is conditioned by the chemical structure of the inhaled anaesthetic molecule. Ether structure is proinflammatory, while CF3 substituents are anti-inflammatory. Therefore, it can be expected that halothane (no ether structure, one CF3 group) and sevoflurane (ether structure, two CF3 groups) show a stronger immunosuppressive effect than isoflurane (ether structure, one CF3 group) and desflurane (ether structure, one CF 3 group).

2. Inhaled anaesthetics may have a beneficial effect on the course of syndromes characterized by severe, generalized inflammatory response such as sepsis, shock, postresuscitation disease, polytrauma, burn disease, acute pancreatitis and ARDS.

3. Inhaled anaesthetics may have a beneficial effect in transplantology, both in autologous transplants (transfer of free tissue flaps) in which we can prevent damage caused by ischemia and reperfusion, as well as in allogeneic transplants (including the "non-heart beating donors") where they may be an induction of the immunosuppressive treatment.

4. The use of inhaled anaesthetics in patients who start to develop Compensatory Antiinflammatory Response Syndrome (CARS), those with pathologies listed in section 2 and congenital or acquired immunodeficiency syndromes (AIDS, immunosuppressive therapy, cachexia) may be associated with particularly severe immunosuppressant effects and the consequent exposure to infectious agents.

5. Inhaled anaesthetics used in patients with cancer can cause neoplastic progression and thus contribute to increased mortality in this group of patients.

\section{REFERENCES}

[1] Kitakaze M. How to mediate cardioprotection in ischemic hearts--accumulated evidence of basic research should translate to clinical medicine. Cardiovasc Drugs Ther 2010;24:217223.

[2] Voigtsberger S, Lachmann RA, Leutert AC, Schlapfer M, Booy C, Reyes L, Urner M, Schild J, Schimmer RC, Beck-Schimmer B. Sevoflurane ameliorates gas exchange and attenuates lung damage in experimental lipopolysaccharide-induced lung injury. Anesthesiology 2009; 111:1238-1248.

[3] Steurer M, Schlapfer M, Z'Graggen BR, Booy C, Reyes L, Spahn DR, Beck-Schimmer B. The volatile anaesthetic sevoflurane attenuates lipopolysaccharide-induced injury in alveolar macrophages. Clin Exp Immunol 2009; 155:224-230. 
[4] De Conno E, Steurer MP, Wittlinger M, Zalunardo MP, Weder W, Schneiter D, Schimmer RC, Klaghofer R, Neff TA, Schmid ER, Spahn DR, Z'Graggen B R, Urner M, BeckSchimmer B. Anesthetic-induced improvement of the inflammatory response to one-lung ventilation. Anesthesiology 2009;110:13161326.

[5] Sharma AK, Fernandez LG, Awad AS, Kron IL, Laubach VE. Proinflammatory response of alveolar epithelial cells is enhanced by alveolar macrophage-produced TNF-alpha during pulmonary ischemia-reperfusion injury. Am J Physiol Lung Cell Mol Physiol 2007;293:L105113.

[6] Beck-Schimmer B, Schimmer RC, Pasch T. The airway compartment: Chambers of secrets. News Physiol Sci 2004;19:129-132.

[7] Ware LB, Koyama T, Billheimer DD, Wu W, Bernard GR, Thompson BT, Brower RG, Standiford TJ, Martin TR, Matthay MA. Prognostic and pathogenetic value of combining clinical and biochemical indices in patients with acute lung injury. Chest 2010;137:288-296.

[8] Schilling T, Kozian A, Kretzschmar M, Huth C, Welte T, Buhling F, Hedenstierna G, Hachenberg T. Effects of propofol and desflurane anaesthesia on the alveolar inflammatory response to one-lung ventilation. Br J Anaesth 2007; 99:368-375.

[9] Guarracino F, Landoni G, Tritapepe L, Pompei F, Leoni A, Aletti G, Scandroglio AM, Maselli D, De Luca M, Marchetti C, Crescenzi G, Zangrillo A. Myocardial damage prevented by volatile anesthetics: A multicenter randomized controlled study. J Cardiothorac Vasc Anesth 2006; 20:477-483.

[10] Beck-Schimmer B, Breitenstein S, Urech S, De Conno E, Wittlinger M, Puhan M, Jochum W, Spahn DR, Graf R, Clavien PA. A randomized controlled trial on pharmacological preconditioning in liver surgery using a volatile anesthetic. Ann Surg 2008;248:909-918.

[11] Welch WD. Halothane reversibly inhibits human neutrophil bacterial killing. Anesthesiology. 1981;55:650-4.

[12] Fröhlich D, Rothe G, Schwall B, Schmid P, Schmitz G, Taeger K, Hobbhahn J. Effects of volatile anaesthetics on human neutrophil oxidative response to the bacterial peptide FMLP. Br J Anaesth. 1997; 78:718-23.

[13] Guochang H, Salem MR, Crystal GJ. Isoflurane prevents platelets from enhancing neutrophilinduced coronary endothelial dysfunction. Anesth Analg. 2005;101:1261-8.

[14] Fan H, Sun B, Gu Q, Lafond-Walker A, Cao S, Becker LC. Oxygen radicals trigger activation of NF- $\kappa \mathrm{B}$ and AP-1 and upregulation of ICAM-
1 in reperfused canine heart. Am J Physiol. 2002;282:H1778-86.

[15] Hu G, Vinten-Johansen J, Salem MR, Zhao ZQ, Crystal GJ. Isoflurane inhibits neutrophilendothelium interactions in the coronary circulation: lack of role for adenosine triphosphate- sensitive potassium channels. Anesth Analg. 2002; 94:849-56.

[16] Vinten-Johansen J. Involvement of neutrophils in the pathogenesis of lethal myocardial reperfusion injury. Cardiovasc Res. 2004;61:481-97.

[17] De Hert SG, Turani F, Mathur S, Stowe DF. Cardioprotection with volatile anesthetics: Mechanisms and clinical implications. Anesth Analg. 2005;100:1584-93.

[18] Kevin LG, Novalija E, Stowe DF. Reactive oxygen species as mediators of cardiac injury and protection: the relevance to anesthesia practice. Anesth Analg. 2005;101:1275-87.

[19] Heine J, Jaeger K, Osthaus A, et al. Anaesthesia with propofol decreases FMLP-induced neutrophil respiratory burst but not phagocytosis compared with isoflurane. $\mathrm{Br} \mathrm{J}$ Anaesth 2000; 85:424-430.

[20] Kotani N, Hashimoto H, Sessler DI, et al. Intraoperative modulation of alveolar macrophage function during isoflurane and propofol anesthesia. Anesthesiology 1998; 89:1125-1132.

[21] Erol A, Reisli R, Reisli I, Kara R, Otelcioglu S. Effects of desflurane, sevoflurane and propofol on phagocytosis and respiratory burst activity of human polymorphonuclear leucocytes in bronchoalveolar lavage. Eur J Anaesthesiol. 2009; 26: 150-4.

[22] Horn NA, de Rossi L, Robitzsch T, Hecker KE, Hutschenreuter G, Rosslant R. The effects of sevoflurane and desflurane in vitro on platetetteukocyte adhesion in whole blood. Anaesthesia 2003; 58: 312-319.

[23] Kusza K, Siemionow M, Nalbantoglu U, Hayes J, Wong KC. Microcirculatory response to halothane and isoflurane anesthesia. Ann Plast Surg. 1999; 43:57-66.

[24] Kusza, K.; Blaszyk, M.; Slemionow, M.; Jurczyk, W. Effects of halothane and isoflurane on leukocytes behaviour in peripheral microcirculation after experimental cardiac arrest. European Journal of Anaesthesiology: 2000;1:47-48

[25] Mielniczuk M, Krokowicz Ł., Grykien C., Kusza K, Siemionow M. Effects of volatile anesthetics on microcirculation during hypovolemia: a comparison of isoflurane and sevoflurane. - Eur. J. Anaesthesiol. 2008; 25 supp 44: 62.

[26] Mobert J., Zahler S., Becker B.F., Conzen P., Inhibition of Neutrophil Activation by Volatile 
Anesthetics Decreases Adhesion to Cultured Human Endothelial Cells. Anesthesiology; 1999, 90: 1372-81.

[27] Lucchinetti E, Ambrosio S, Aguirre J, Herrmann P, Harter L, Keel M, Meier T, Zaugg M. Sevoflurane inhalation at sedative concentrations provides endothelial protection against ischemia-reperfusion injury in humans. Anesthesiology 2007; 106:262-268.

[28] Feng J, Zuo Z. Isoflurane preconditioning increases endothelial cell tolerance to in vitro simulated ischemia. J Pharm Pharmacol. 2011; 63: 106-110.

[29] Tait AR, Davidson BA, Johnson KJ, Remick DG, Knight PR. Halothane inhibits the intraalveolar recruitment of neutrophils, lymphocytes, and macrophages in response to influenza virus infection in mice. Anesth Analg. 1993;76:1106-13.

[30] Boost KA, Flondor M, Hofstetter C, Platacis I, Stegewerth K, Hoegl S, et al. The betaadrenoceptor antagonist propranolol counteracts anti-inflammatory effects of isofl urane in rat endotoxemia. Acta Anaesthesiol Scand. 2007;51:900-8.

[31] Tschaikowsky K, Ritter J, Schröppel K, Kühn M. Volatile anesthetics differentially affect immunostimulated expression of inducible nitric oxide synthase: role of intracellular calcium. Anesthesiology. 2000;92:1093-102.

[32] Reutershan J, Chang D, Hayes JK, Ley K. Protective effects of isoflurane pretreatment in endotoxin-induced lung injury. Anesthesiology. 2006; 104:511-7.

[33] Hofstetter C, Flondor M, Boost KA, Koehler P, Bosmann M, Pfeilschifter J, Zwissler B, Mühl H. A brief exposure to isoflurane $(50 \mathrm{~s})$ significantly impacts on plasma cytokine levels in endotoxemic rats. Int Immunopharmacol. 2005;5:1519-22.

[34] Hofstetter C, Boost KA, Flondor M, BasaganMogol E, Betz C, Homann M, Mühl H, Pfeilschifter J, Zwissler B. Anti-infl ammatory effects of sevoflurane and mild hypothermia in endotoxemic rats. Acta Anaesthesiol Scand. 2007;51:893-9.

[35] Woods GM, Griffi ths DM. Reversible inhibition of natural killer cell activity by volatile anaesthetic agents in vitro. $\mathrm{Br} \mathrm{J}$ Anaesth. 1986;58:535-9.

[36] Markovic SN, Knight PR, Murasko DM. Inhibition of interferon stimulation of natural killer cell activity in mice anesthetized with halothane or isoflurane. Anesthesiology. 1993;78:700-6.

[37] Melamed R, Bar-Yosef S, Shakhar G, Shakhar $\mathrm{K}$, Ben-Eliyahu S. Suppression of natural killer cell activity and promotion of tumor metastasis by ketamine, thiopental, and halothane, but not by propofol: mediating mechanisms and prophylactic measures. Anesth Analg. 2003; 97:1331-9.

[38] Moudgil GC, Singal DP. Halothane and isoflurane enhance melanoma tumour metastasis in mice. Can J Anaesth. 1997; 44:904.

[39] Markovic SN, Murasko DM. Anesthesia inhibits interferoninduced natural killer cell cytotoxicity via induction of CD8+ suppressor cells. Cell Immunol. 1993; 151:474-80.

[40] Ferrero E, Ferrero ME, Marni A, Zocchi MR, Stella L, Rugarli C, Tiengo M. In vitro effects of halothane on lymphocytes. Euro J Anaesthesiol. 1986;3:321-30.

[41] Hamra JG, Yaksh TL. Halothane inhibits T cell proliferation and interleukin-2 receptor expression in rats. Immunopharmacol Immunotoxicol. 1996;18:323-36.

[42] Mitsuhata H, Shimizu R, Yokoyama MM. Suppressive effects of volatile anesthetics on cytokine release in human peripheral blood mononuclear cells. Int J Immunopharmacol. 1995; 17:529-34.

[43] Matsuoka H, Kurosawa S, Horinouchi T, Kato M, Hashimoto Y. Inhalation anesthetics induce apoptosis in normal peripheral lymphocytes in vitro. Anesthesiology. 2001;95:1467-72.

[44] Loop T, Dovi-Akue D, Frick M, Roesslein M, Egger L, Humar M, Hoetzel A, Schmidt R, Borner C, Pahl H, Geiger KK, Pannen BHJ. Volatile anesthetics induce caspase-dependent, mitochondria-mediated apoptosis in human $\mathrm{T}$ lymphocytes in vitro. Anesthesiology. 2005; 102:1147-57.

[45] Loop T, Scheiermann P, Doviakue D, Musshoff F, Humar M, Roesslein M, Hoetzel A, Schmidt R, Madea B, Geiger K, Pahl H, Pannen BH. Sevoflurane inhibits phorbol-myristateacetateinduced activator protein-1 activation in human $\mathrm{T}$ lymphocytes in vitro: potential role of the p38-stress kinase pathway. Anesthesiology. 2004;101:710-21.

[46] Schneemilch CE, Ittenson A, Ansorge S, Hachenberg T, Bank U. Effect of 2 anesthetic techniques on the postoperative proinflammatory and anti-infl ammatory cytokine response and cellular immune function to minor surgery. J Clin Anesth. 2005; 17:51727.

[47] Inada T, Yamanouchi Y, Jomura S, Sakamoto S, Takahashi M, Kambara T, Shingu K. Effect of propofol and isoflurane anaesthesia on the immune response to surgery. Anaesthesia. 2004;59:954-9.

[48] Schneemilch CE, Hachenberg T, Ansorge S, Ittenson A, Bank U. Effects of different anaesthetic agents on immune cell function in vitro. Eur J Anaesthesiol. 2005;22:616-23. 
The Anti-Inflammatory and Immunosuppressive Properties of Inhaled Anaesthetics - Data from Experimental Studies and Clinical Implications

[49] Urner M, et al., Fluorinated groups mediate the immunomodulatory effects of volatile anesthetics in acute cell injury. Am J Respir Cell Mol Biol. 2011; 45: 617-24.

[50] Yue T, Roth Z'graggen B, Blumenthal S, Neff SB, Reyes L, Booy C, Steurer M, Spahn DR,
Neff TA, Schmid ER, Beck-Schimmer B. Postconditioning with a volatile anaesthetic in alveolar epithelial cells in vitro. Eur Respir J 2008;31:118-125.

Citation: Mariusz Mielniczuk. The Anti-Inflammatory and Immunosuppressive Properties of Inhaled Anaesthetics - Data from Experimental Studies and Clinical Implications. ARC Journal of Anesthesiology. 2017;2(4):1-9. doi: dx.doi.org/10.20431/2455-9792.0204001.

Copyright: (C) 2017 Authors. This is an open-access article distributed under the terms of the Creative Commons Attribution License, which permits unrestricted use, distribution, and reproduction in any medium, provided the original author and source are credited. 